\title{
Altitude and latitude have different effects on population characteristics of the widespread plant Anthyllis vulneraria
}

\author{
Laura Daco ${ }^{1,2,3}$ (1) $\cdot$ Guy Colling ${ }^{2}$ (D) $\cdot$ Diethart Matthies $^{1}$ (D)
}

Received: 1 October 2020 / Accepted: 27 August 2021/ Published online: 2 October 2021

(c) The Author(s) 2021

\begin{abstract}
Widespread plants may provide natural models for how population processes change with temperature and other environmental variables and how they may respond to global change. Similar changes in temperature can occur along altitudinal and latitudinal gradients, but hardly any study has compared the effects of the two types of gradients. We studied populations of Anthyllis vulneraria along a latitudinal gradient from Central Europe to the range limit in the North and an altitudinal gradient in the Alps from $500 \mathrm{~m}$ to the altitudinal limit at $2500 \mathrm{~m}$, both encompassing a change in annual mean temperature of $\mathrm{c}$. $11.5^{\circ} \mathrm{C}$. Plant size and reproduction decreased, but plant density increased along both gradients, indicating higher recruitment and demographic compensation among vital rates. Our results support the view that demographic compensation may be common in widespread species in contrast to the predictions of the abundant centre model of biogeography. Variation in temperature along the gradients had the strongest effects on most population characteristics, followed by that in precipitation, solar radiation, and soil nutrients. The proportion of plants flowering, seed set and seed mass declined with latitude, while the large variation in these traits along the altitudinal gradient was not related to elevation and covarying environmental variables like annual mean temperature. This suggests that it will be more difficult to draw conclusions about the potential impacts of future climate warming on plant populations in mountains, because of the importance of small-scale variation in environmental conditions.
\end{abstract}

Keywords Abundant centre model $\cdot$ Climate change $\cdot$ Environmental gradients $\cdot$ Herbivory $\cdot$ Seed set

\section{Introduction}

Temperature is an important determinant of plant physiology and distribution (Woodward 1987; De Frenne et al. 2013). Climatic factors such as low temperatures and short growing seasons typically constrain plant growth and cause absolute limits to plant growth in arctic and alpine environments

Laura Daco

ldaco@mnhn.lu

Guy Colling

gcolling@mnhn.lu

Diethart Matthies

matthies@staff.uni-marburg.de

1 Department of Biology, University of Marburg, Karl-von-Frisch-Str. 8, 35043 Marburg, Germany

2 Musée national d'histoire naturelle, 25 rue Münster, L-2160 Luxembourg, Luxembourg

3 Fondation Faune-Flore, 24 rue Münster, L-2160 Luxembourg, Luxembourg
(Woodward 1987; Körner 2003; Halbritter et al. 2013). According to the altitude-for-latitude temperature model, similar changes in annual mean temperature of c. $5^{\circ} \mathrm{C}$ occur over $1000 \mathrm{~m}$ of altitude and $1000 \mathrm{~km}$ of latitude in the temperate zone (Jump et al. 2009). Studies of population traits along gradients of altitude and latitude with comparable changes in temperature provide an opportunity to study the influence of temperature and other environmental factors on plant population characteristics and structure. The study of natural variation in ecologically important traits is crucial to further increase our knowledge of the mechanisms involved in the distribution and abundance of plant species (Jump et al. 2009).

Global warming is expected to affect the range and abundance of species in the future (Walther 2003; Thomas 2010; Swab et al. 2015). The global mean surface temperature is projected to increase during this century by up to $4.8^{\circ} \mathrm{C}$ (IPCC 2014). An improved understanding of how climatic conditions influence plants is important for assessing the response of plants to global change and 
to conserve threatened plant species under changing climatic conditions. Plant species with populations occurring along strong gradients in altitude or latitude and corresponding strong changes in temperature may provide natural models for how population processes change with temperature (Halbritter et al. 2013).

However, altitudinal and latitudinal gradients differ in a number of factors including atmospheric pressure, precipitation, solar radiation, and soil nutrients (Körner 2007; De Frenne et al. 2013). The response of species across the two types of gradients may thus be expected to differ in potentially important aspects. While many studies have investigated different processes in plant populations along either altitudinal (Totland 2001; Pellissier et al. 2010; Rasmann et al. 2014) or latitudinal gradients (Sagarin et al. 2006; Moeller et al. 2017), there are hardly any studies that have compared the effect of the two types of gradients on populations of a single species (Siefert et al. 2015). Moreover, most studies did not try to disentangle the effects of temperature on plants from those of other environmental factors (De Frenne et al. 2013).

The aim of this study was to compare populations of Anthyllis vulneraria L. (Fabaceae) along two temperature gradients of c. $10{ }^{\circ} \mathrm{C}$, a latitudinal gradient of $\mathrm{c}$. $2400 \mathrm{~km}$ from Central Europe to northern Norway and three altitudinal gradients of c. $2000 \mathrm{~m}$ in the European Alps. We analysed climatic conditions using data from Worldclim (Fick and Hijmans 2017), soil nutrients and site productivity and investigated characteristics of the populations including their size and density, size-related plant traits, reproduction, pre-dispersal seed predation, and population structure. The altitudinal gradient spanned the species' range from lowland sites to populations at the altitudinal limit and the latitudinal gradient ranged from the geographical centre of the distribution to the northern distribution limit. These gradients allowed us to test some of the predictions of the abundant centre model (ACM; Brown 1984; Sagarin and Gaines 2002) of biogeography. The ACM predicts that the abundance and performance of species at the geographical periphery of their distribution area are lower than those at the centre of their range where environmental conditions are assumed to be most suitable (Abeli et al. 2014; Pironon et al. 2017).

We address the following questions: (1) How do population characteristics of $A$. vulneraria vary along the two gradients and do altitude and latitude have different effects? (2) Which environmental variables in addition to temperature are important predictors of population characteristics along altitudinal and latitudinal gradients? (3) Are characteristics of the populations along both gradients in line with the predictions of the ACM?

\section{Material and methods}

\section{Study species}

Anthyllis vulneraria is a very polymorphic biennial or perennial occurring in nutrient-poor calcareous grasslands and screes all across Europe, the Mediterranean Basin and the Caucasus (GBIF.org 2019) from sea level up to $3000 \mathrm{~m}$ a.s.l. (Conert 1975). In total, 24 infraspecific taxa have been described in Europe (Cullen 1968). However, a phylogenetic study based on ITS sequences and chloroplast microsatellites showed that all subspecies of $A$. vulneraria clustered together and thus did not support the traditional taxonomic subdivisions based on morphology (Nanni et al. 2004). Moreover, AFLP variance in a study of eight taxa of A. vulneraria did not support recognizing intraspecific taxa of $A$. vulneraria at the species or subspecies level (Köster et al. 2008). In contrast to earlier studies which argued that subspecies do not interbreed due to the predominantly autogamous reproductive system (Couderc 1971; Couderc and Gorenflot 1978) more recent studies based on molecular markers found that there is considerable gene flow among and within populations (Honnay et al. 2006; Van Glabeke et al. 2007; Kesselring et al. 2015) indicating that the populations are not predominantly selfing. In the present study, we will therefore not distinguish between putative subspecies a priori to capture a large amount of variation over the whole study area. The basal leaves of A. vulneraria form rosettes and the flowers are grouped into flowerheads with four to more than 20 flowers. Plants usually start flowering in the second year after germination, but flowering can be delayed for up to eight years (Erschbamer and Retter 2004). Most plants are monocarpic but some may flower more than once (Sterk 1975). Flowers are pollinated by Hymenoptera (Couderc and Gorenflot 1978) and produce a single seed per fruit. An important specialist herbivore of A. vulneraria are the caterpillars of Cupido minimus (Lepidoptera) which feed on the developing seeds (Krauss et al. 2004). Although A. vulneraria is not considered to be endangered in most parts of its distribution, it has strongly declined in some areas in the last decades, e.g. in NE Germany (Jansen et al. 2019).

\section{Altitudinal and latitudinal gradients}

We studied the influence of environmental conditions on A. vulneraria in 40 populations along an altitudinal and a latitudinal gradient. The length of the two gradients was chosen to correspond to a change of $11.5^{\circ} \mathrm{C}$ in annual mean temperature. The latitudinal gradient ranged from 
the centre of the distribution in Central Europe $\left(46.4^{\circ} \mathrm{N}\right)$ over $2400 \mathrm{~km}$ to the northern distribution limit in Scandinavia $\left(68.1^{\circ} \mathrm{N}\right)$ and the altitudinal gradient from valley populations in the Alps at $500 \mathrm{~m}$ to the altitudinal limit at $2500 \mathrm{~m}$ a.s.l. To account for potential regional climatic differences, the altitudinal gradient was replicated in three different alpine regions in France, Switzerland and Austria.

\section{Field data}

Based on information gathered from local botanists and the GBIF database (GBIF.org 2019), we sampled 20 A. vulneraria populations each along the altitudinal and the latitudinal gradients (Fig. 1; Supplementary Material Table S1). A population was defined as a group of plants separated by at least $100 \mathrm{~m}$ from the next conspecific plants. During summer 2015, we recorded at each site the altitude above sea level, latitude and longitude with a GPS (eTrex 20, Garmin Ltd.), site exposition as absolute deviation from the north with a compass and inclination with a clinometer. Populations were sampled at a similar phenological state, i.e. southern and lowland populations were sampled first. In small populations, all plants of $A$. vulneraria were counted. In large populations, the population size was estimated from counts in parts of the total area. To estimate site productivity, we sampled in each population the above-ground biomass in two randomly chosen plots $(25 \mathrm{~cm} \times 25 \mathrm{~cm})$ in which $A$. vulneraria was present. The vegetation was clipped at $5 \mathrm{~cm}$ above soil level, dried at $60^{\circ} \mathrm{C}$ for $48 \mathrm{~h}$ to constant mass and
Fig. 1 Map of the Anthyllis vulneraria study sites in Europe. The inset shows the locations of the populations of the altitudinal gradient in France, Switzerland and Austria

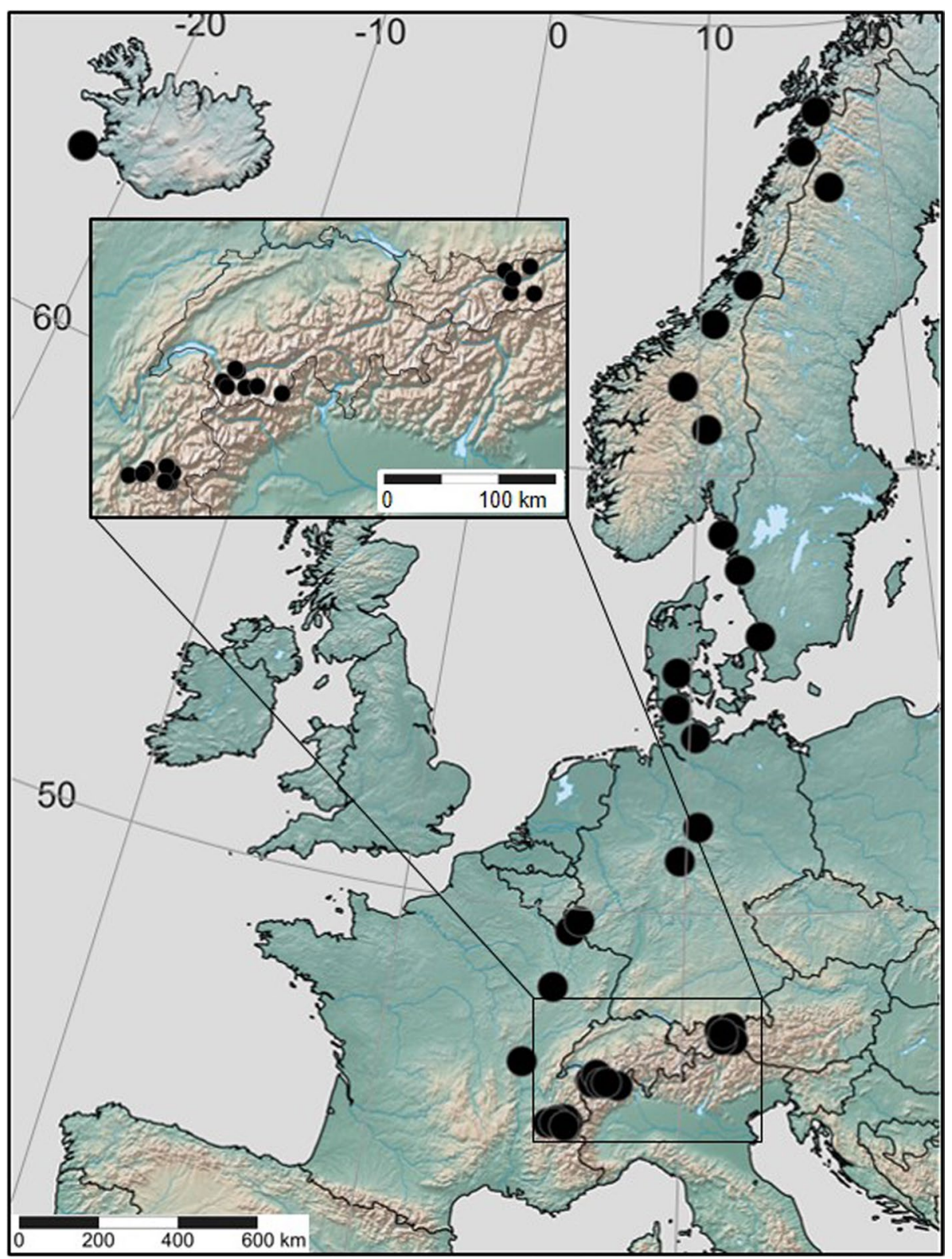


weighed. At each site, we took at least three random samples of a total of at least $300 \mathrm{~g}$ of mineral soil. Soil organic carbon was determined by subtracting the inorganic carbon content measured with phosphoric acid from the total carbon content determined by dry combustion at $1200{ }^{\circ} \mathrm{C}$ with a Multi EA 4000 (Analytik Jena, Jena, Germany). Total nitrogen content was determined by dry combustion at $900{ }^{\circ} \mathrm{C}$ with an elemental analyzer (Vario MAX cube, Elementar, Langenselbold, Germany). The $\mathrm{pH}$ was measured in a $0.01 \mathrm{M}$ solution of $\mathrm{CaCl}_{2}$ with a $\mathrm{SP} 2000 \mathrm{pH}$ soil analyser (Skalar Analytical, Breda, Netherlands). Phosphorus $\left(\mathrm{P}_{2} \mathrm{O}_{5}\right)$ and potassium $\left(\mathrm{K}_{2} \mathrm{O}\right)$ were extracted with a $0.05 \mathrm{M}$ calcium lactate and acetate solution and the contents were dosed by inductively coupled plasma optical emission spectrometry (Agilent 725 ICP-OES Radial, Santa Clara, USA).

In each population, we selected one plot of $1 \mathrm{~m} \times 1 \mathrm{~m}$ in an area which appeared to have the highest density of $A$. vulneraria and two further plots located at random but with A. vulneraria present. In each plot, we counted the number of flowerheads of $A$. vulneraria and of flowering plants and calculated the mean number of flowerheads per plant and the mean per population. In the three plots, we determined the sum of the number of vegetative and of flowering A. vulneraria individuals and calculated the proportion of flowering plants per population.

In each population we collected all flowerheads from 20 fruiting plants along a $20 \mathrm{~m}$ long transect. We determined the height for each of these plants. In the laboratory, we determined for each mother plant the number of healthy seeds (green and large), fully developed but damaged seeds with clear signs of herbivory, and aborted seeds (small, brown or light green). We calculated seed set per population as [number of intact and damaged seeds collected/total number of seeds including aborted], and the proportion of damaged seeds as [sum of damaged seeds/total number of seeds]. The presence of eggs of Cupido minimus in the collected flowerheads was recorded for each population. For each mother plant, the mean mass of healthy seeds was determined and then averaged to calculate mean seed mass per population.

\section{Bioclimatic variables}

For each population, we downloaded three climatic variables from the WorldClim database Version 2.0 (Fick and Hijmans $2017)$ in a 30 arc-seconds $\left(1 \mathrm{~km}^{2}\right)$ resolution: annual mean temperature, annual precipitation, and solar radiation.

\section{Statistical analyses}

If not stated otherwise, all statistical analyses were carried out using IBM SPSS Statistics for Windows, version 25.0 (IBM Corp., Armonk, N.Y., USA). To study the environmental changes with latitude and altitude, we analysed the relationships between altitude or latitude and annual mean temperature, annual precipitation, solar radiation, standing biomass, soil organic carbon content, nitrogen, phosphorus, and potassium content with linear regressions.

The effects of altitude and latitude on population means of morphological and reproductive traits were tested with general and generalized linear models (GLMs) in R 3.5.2 ( $\mathrm{R}$ Core Team 2018). These analyses investigated also whether mean plant performance declined continuously from the centre of the distribution to the range margins at high latitudes and altitudes as predicted by the abundant centre model. The GLMs for proportion data (e.g. proportion flowering, seed set, seeds damaged) were calculated with a logit link and a quasibinomial error distribution (see Crawley 2009). For the altitudinal gradient, the effects of the three regions within the Alps and the linear and quadratic effects of altitude as well as the interaction between the region and the linear and the quadratic terms were tested. The quadratic term was integrated to check for a potential mid-elevational maximum along the gradient. Similarly, linear and quadratic effects of latitude were also tested; however, the quadratic terms were never significant. Models were simplified by dropping non-significant terms $(P>0.05)$. For proportion data, McFadden's Pseudo $r^{2}$ was calculated as one minus the ratio between the log-likelihood of the model of interest and the log-likelihood of the null model. When region had a significant effect (only in the case of maximum density), the $r^{2}$ of the model for each region was calculated by correlating the predicted values from the overall model and the observed values. To study the possible effects of altitude or latitude, population size and maximum plant density on the presence of eggs of Cupido minimus, we carried out separate logistic regressions. Due to overdispersion, we used quasibinomial error distributions in the GLMs. We compared the strength of the relationships of mean values of population traits and altitude with the relationship of the same traits with latitude with Z-tests using the R-package cocor (Diedenhofen and Musch 2015).

We performed a principal component analysis (PCA) based on correlations with soil organic carbon, total nitrogen and phosphorus $\left(\mathrm{P}_{2} \mathrm{O}_{5}\right)$ contents to characterize soil conditions at the study sites. The resulting PCA factor (PC Soil nutrients) explained $77.8 \%$ of the total variance of the component variables and was used in multiple regressions as an explanatory environmental variable. Factor loadings were 0.96 for $N_{\text {tot }}, 0.79$ for $\mathrm{P}_{2} \mathrm{O}_{5}$, and 0.89 for $C_{\text {org }}$. To elucidate which environmental variables might be responsible for the observed relationships between certain population characteristics and latitude or altitude, we performed (generalized) linear models with normal or quasibinomial errors relating these characteristics to the following explanatory variables: annual mean temperature, 
Table 1 Correlations between altitude and various habitat characteristics for the 20 altitudinal populations and latitude and various habitat characteristics for the 20 latitudinal gradient populations separately. $(*) P<0.1 ; * P<0.05 ; * * P<0.01 ; * * *<0.001$. ${ }^{\text {a }}$ Sample size $N=19$

\begin{tabular}{|c|c|c|c|}
\hline \multicolumn{2}{|l|}{ Habitat variable } & $\begin{array}{l}\text { Altitude } \\
r\end{array}$ & $\begin{array}{l}\text { Latitude } \\
r\end{array}$ \\
\hline \multicolumn{2}{|l|}{ Annual mean temperature $\left({ }^{\circ} \mathrm{C}\right)$} & $-0.98 * * *$ & $-0.87 * * *$ \\
\hline \multicolumn{2}{|l|}{ Annual precipitation (mm) } & $0.63 * *$ & 0.28 \\
\hline \multirow[t]{4}{*}{ Solar radiation $\left(\mathrm{kJ} / \mathrm{m}^{2}\right.$ day $)$} & All sites & 0.33 & $-0.95 * * *$ \\
\hline & France & $0.99 * * *$ & \\
\hline & Switzerland & $0.94 * *$ & \\
\hline & Austria & $0.82(*)$ & \\
\hline \multicolumn{2}{|l|}{ Standing biomass $\left(\mathrm{g} / \mathrm{m}^{2}\right)$} & $-0.40(*)^{\mathrm{a}}$ & 0.36 \\
\hline \multicolumn{2}{|c|}{ Organic carbon soil content (\%) } & $0.06^{\mathrm{a}}$ & $-0.49 *$ \\
\hline \multicolumn{2}{|l|}{ Nitrogen soil content $(\%)$} & $0.14^{\mathrm{a}}$ & $-0.57 * *$ \\
\hline \multicolumn{2}{|l|}{$\begin{array}{l}\text { Phosphorus soil content } \\
\text { (mg/100 g soil) }\end{array}$} & $0.17^{\mathrm{a}}$ & $-0.48^{*}$ \\
\hline \multicolumn{2}{|l|}{$\begin{array}{l}\mathrm{K}_{2} \mathrm{O} \text { soil content }(\mathrm{mg} / 100 \mathrm{~g} \\
\text { soil) }\end{array}$} & $-0.07^{\mathrm{a}}$ & -0.33 \\
\hline
\end{tabular}

annual precipitation, solar radiation, PC Soil nutrients, standing biomass (see Supplementary Material Table S2). For each plant trait we calculated all possible models and their Akaike information criteria (AICc) or the quasi AICc (QAICc; for proportion data) using the function dredge of the R-package MuMIn (Barton 2019). To assess the importance of the individual predictors we averaged all possible models including these predictors (conditional average, Burnham and Anderson 2002) and derived importance values. In addition, we selected the model with the lowest AICc or QAICc. The $r^{2}$ of those models was calculated by correlating the predicted and the observed values for the Gaussian data and by calculating Mc Fadden's pseudo $r^{2}$ in the case of proportion data. We calculated standardized regression coefficients for the variables in these models. Standardized regression coefficients for the GLMs for proportion data were calculated using the latent-theoretical method (Grace et al. 2018).

In the analyses, data for population size, maximum plant density and mean number of flowerheads per plant were log-transformed prior to analysis to achieve normally distributed residuals and homoscedasticity. Population AAt5 was excluded from most of the analyses due to missing data (except for population size, max. plant density, seed set, seeds damaged and seed mass).

\section{Results}

\section{Habitat characteristics and gradients}

Most study sites had a southern exposition (median $=114.5^{\circ}$ deviation from north) indicating that $A$. vulneraria prefers well-exposed habitats (Supplementary Material Table S3). Anthyllis vulneraria was present at both level sites and slopes of up to $103 \%$ inclination. Standing biomass was generally low (median $=96.1 \mathrm{~g} / \mathrm{m}^{2}$ ) indicating little competition for light. Soils were slightly acidic to neutral (median $\mathrm{pH}=7.1$ ) and the nutrient content was generally low (medians: $N_{\text {tot }}=0.2 \%, \mathrm{P}_{2} \mathrm{O}_{5}<3.0 \mathrm{mg} / 100 \mathrm{~g}$ soil, $\mathrm{K}_{2} \mathrm{O}=8.0 \mathrm{mg} / 100 \mathrm{~g}$ soil, $C_{\text {org }}=3.2 \%$ ). The range of annual mean temperatures at the study sites was similar for both the altitudinal $(-0.4$ to $10.8{ }^{\circ} \mathrm{C}$ ) and the latitudinal gradients $\left(-1.2\right.$ to $\left.10.8{ }^{\circ} \mathrm{C}\right)$. Annual mean temperature decreased with both increasing altitude and latitude (Table 1, Supplementary Material Fig. S1).

Several other environmental variables changed along the gradients of altitude and latitude (Table 1). With increasing altitude precipitation increased and standing biomass decreased, while with increasing latitude solar radiation, soil N, P and organic C decreased. Potassium (K) soil content did not vary along the gradients.

\section{Population characteristics and mean plant traits along the altitudinal and latitudinal gradients}

The relationship between maximal plant density and altitude was best fitted by quadratic functions (Fig. 2a, Supplementary Material Table S4). While in the Austrian and French Alps these functions indicated that plant density was highest at c. $1700 \mathrm{~m}$, in Switzerland plant density increased up to $2500 \mathrm{~m}$. However, the decline in density above $1800 \mathrm{~m}$ in Austria and above $2000 \mathrm{~m}$ in France was in both regions due to only a single population. Maximum plant density in the populations increased with latitude (Fig. 2b). In the 40 studied populations the number of plants and the maximum density were positively correlated 
Fig. 2 Relationships between characteristics of populations of $A$. vulneraria with altitude and latitude. For the altitudinal gradient, the effects of the three regions within the Alps were significant only in the case of maximum density (a) resulting in distinct models for each region. The results of $Z$-tests shown in between the panels indicate the significance of differences in the two correlation coefficients showing the strength of the relationship between a population trait and altitude or latitude. The $Z$-tests between the correlation coefficients of maximum density and altitude or latitude were calculated for the three regions separately

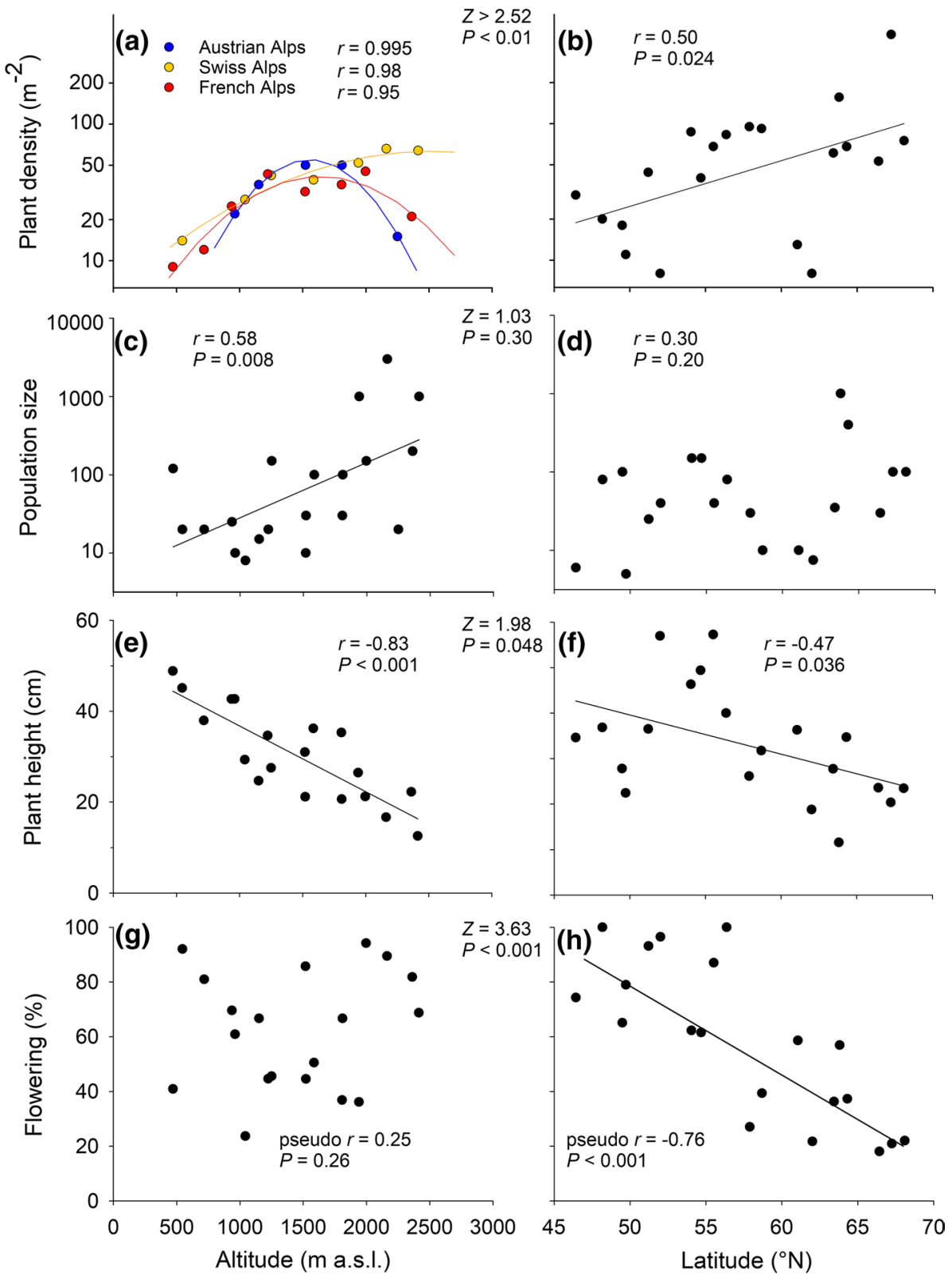

( $r=0.43, P<0.01)$. Population size varied along the altitudinal gradient from 80 to 30,000 individuals and along the latitudinal gradient from 50 to 10,000 . The size of the populations increased significantly with altitude (Fig. 2c) but not with latitude (Fig. 2d). However, the difference in the strength of the relationships was not significant.

Plant height decreased with both altitude and latitude indicating that both gradients were limiting plant growth, but altitude was a much better predictor (Fig. 2e, f). In contrast, the proportion of flowering plants did not vary consistently with altitude (Fig. 2g), but strongly decreased with latitude (Fig. 2h). The number of flowerheads per plant decreased from c. nine in the low altitude to four in the high altitude populations (Fig. 3a) and from 17 in the
Central European to five in the arctic populations (Fig. 3b). The mean number of flowerheads per plant was related to mean plant size in the 40 populations as it increased with plant height $(r=0.52, P<0.001)$.

Seed set decreased with latitude (Fig. 3d), but there was no relationship with altitude (Fig. 3c). However, the difference between the two correlation coefficients was only significant at the 0.08 level. The proportion of seeds damaged by herbivory decreased with both altitude and latitude (Fig. 3e, f). We detected eggs of Cupido minimus in 27 of the 40 sites but did not find any significant relationships between the probability of their presence and altitude $(P=0.96)$, latitude $(P=0.50)$, population size (Alt.: $P=0.42$; Lat.: $P=0.10$ ) or density of $A$. vulneraria (Alt.: $P=0.66$; Lat.: 
Fig. 3 Relationships between mean reproductive traits in populations of $A$. vulneraria with altitude and latitude. A regression line was added if $P<0.1$. The results of $Z$-tests shown in between the panels indicate the significance of differences in the two correlation coefficients showing the strength of the relationship between a population trait and altitude or latitude

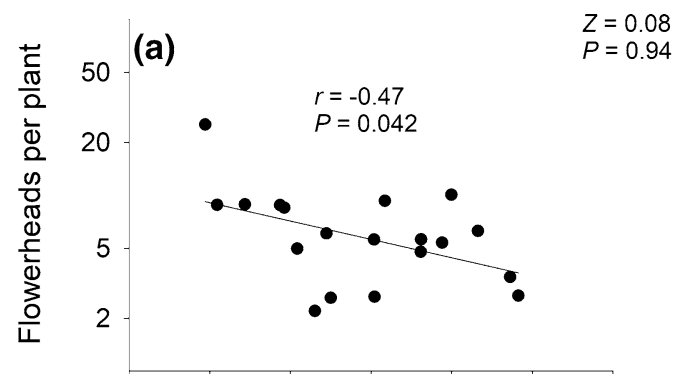

(b)
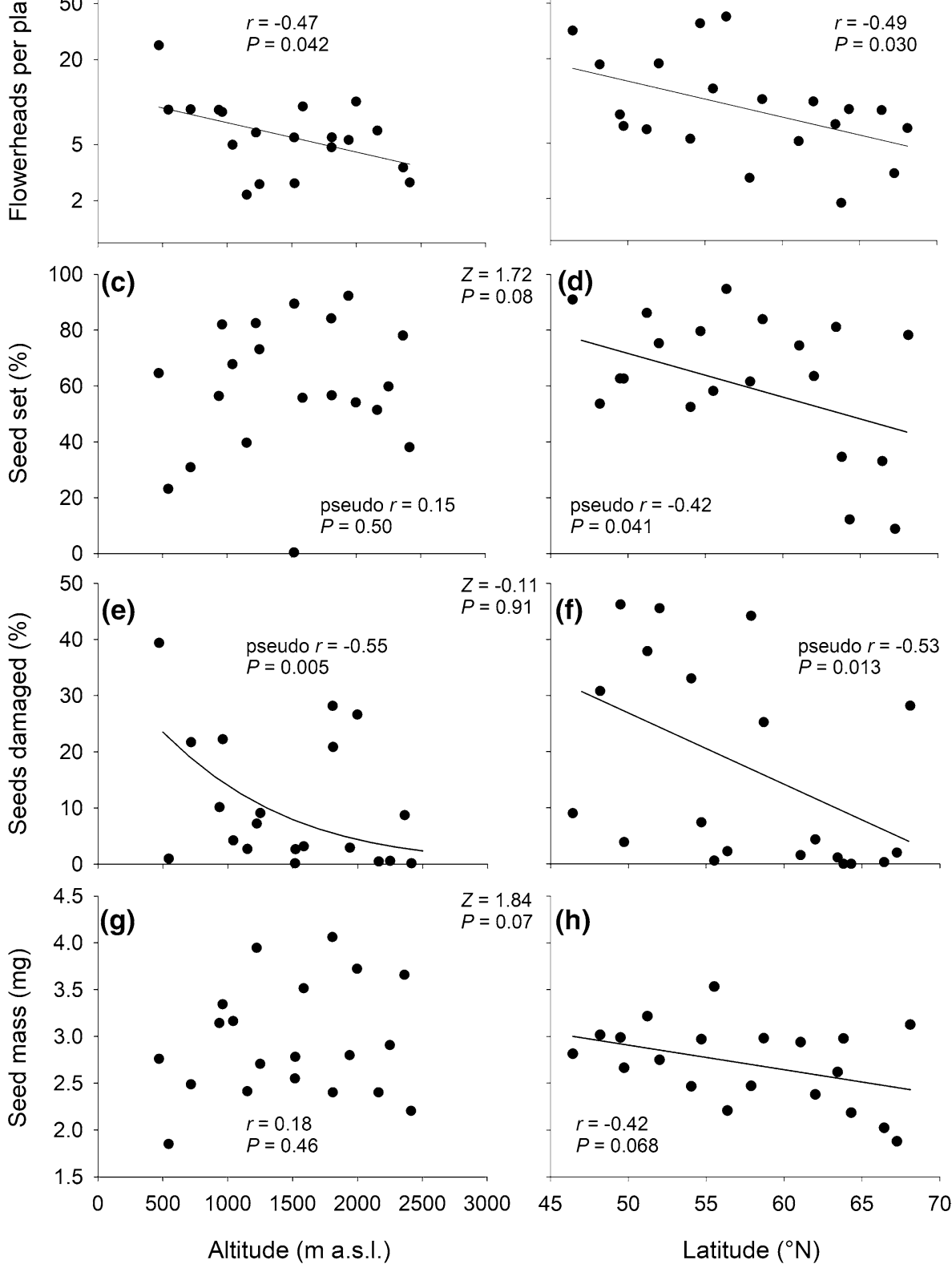

(h)

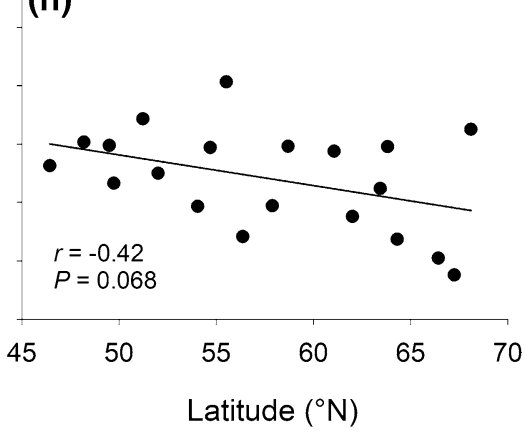

$P=0.19)$. There was no clear relationship between mean seed mass and altitude (Fig. 3g), while there was some support $(P=0.068)$ that seed mass decreased with latitude (Fig. 3h). The difference between the two correlation coefficients was only significant at the 0.07 level.

\section{Influences of habitat characteristics on mean population traits}

Annual mean temperature was the environmental factor that was most important in the models for six out of eight mean population traits along the altitudinal gradient (Fig. 4, Supplementary Material Table S5). Along the latitudinal gradient, temperature had also the highest importance values for most traits. Precipitation had overall the second highest importance. In the best models with the lowest AICc (Supplementary Material Table S6) mean plant performance in terms of growth and reproduction declined in parallel with temperature along both gradients, but density and population size increased with lower temperatures in the higher regions of the Alps. Precipitation, soil nutrients and solar radiation were further environmental factors that influenced some plant traits, although 
Fig. 4 The effects of annual mean temperature (Temp), annual precipitation (Prec), solar radiation (Solar), PC soil nutrients (Nutri), and standing biomass (Biom) on mean population characteristics of Anthyllis vulneraria along an altitudinal and a latitudinal gradient. Given are importance values from averaging over all possible models including these variables. For variables that are part of the best model with the lowest AICc (Supplementary Material Table S6) the sign of the regression coefficient is shown: +, positive; -, negative effect. For model details see Supplementary Material Table S5 (a) Max. plant density

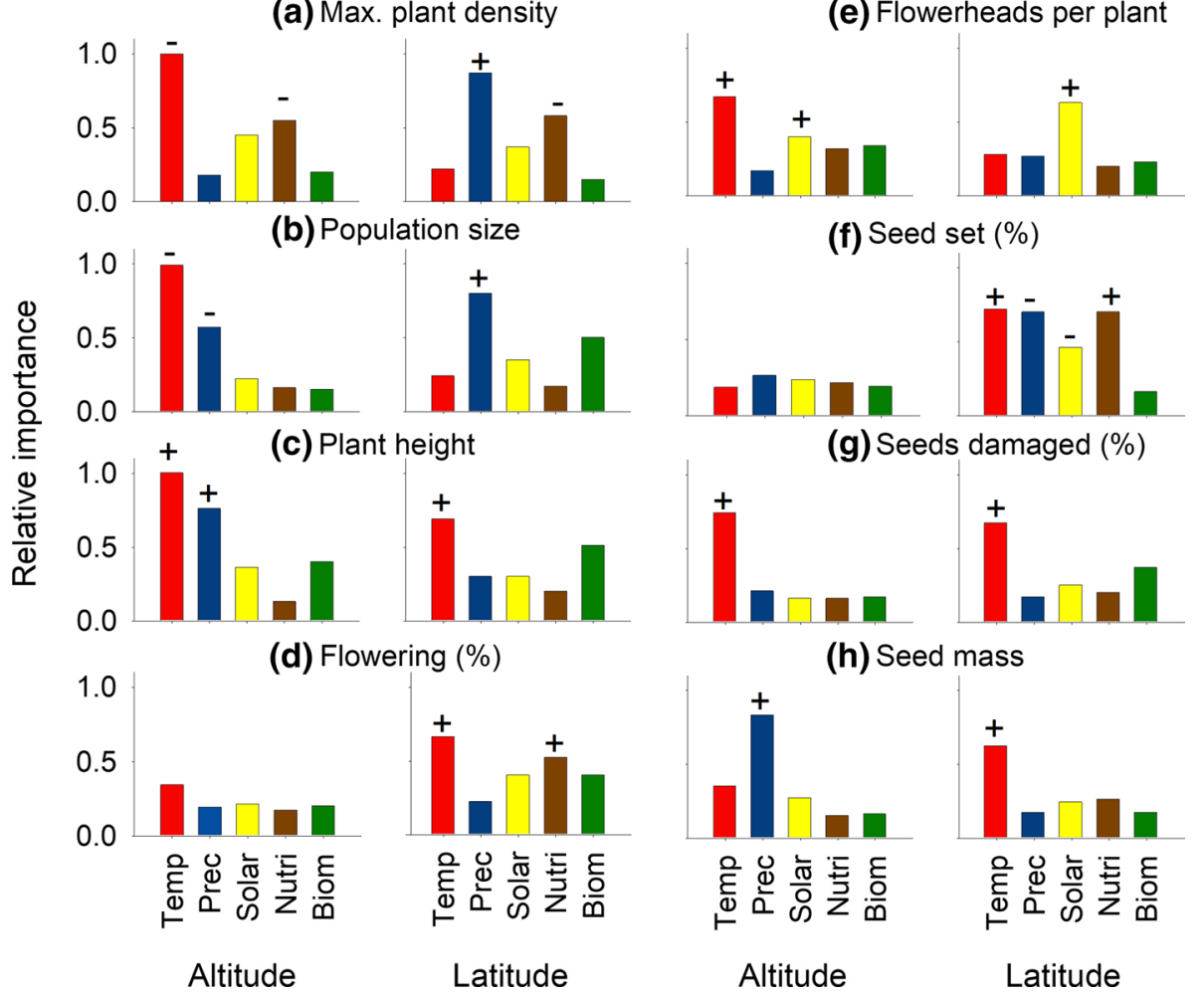

mostly in addition to temperature while standing biomass was never part of the best model.

\section{Discussion}

We studied mean population traits of $A$. vulneraria along a latitudinal gradient that extended from the centre of the distribution of the species in Central Europe to its northern distributional margin, and along an altitudinal gradient that ranged from the lowlands to the altitudinal limit of the species in the Alps. Plant size, reproduction and density reacted similarly to changes in altitude and latitude and showed clinal variation, potentially allowing to assess the response of populations to predicted warming of the climate. However, some reproductive components like seed set and mass and the proportion of plants flowering responded differently to the two gradients and decreased with latitude but not with altitude indicating that the effects of climate warming on plant populations are likely to differ along the two gradients.

The abundant centre model predicts that all vital rates of a species like survival, reproduction, growth and recruitment are highest at the centre of the distribution of a species, where environmental conditions are assumed to be most suitable and decline towards the periphery (Brown 1984; Pironon et al. 2017). The reduced size and reproduction of A. vulneraria in peripheral northern and alpine populations were in line with the decline in plant performance towards the periphery predicted by the ACM (see e.g. also Jump and Woodward 2003; Angert 2006; Vaupel and Matthies 2012). However, only $43 \%$ of the studies reviewed by Pironon et al. (2017) found a significant decline of reproduction towards the periphery, while a further $21 \%$ found no clear pattern. In contrast to size and reproduction, the density of $A$. vulneraria increased along both the altitudinal and latitudinal gradients, indicating that recruitment must be much higher in peripheral high altitude and high latitude populations to more than compensate for the reduced reproduction. The higher recruitment in peripheral populations could be the result of higher survival of young plants due to the higher precipitation and the lower intraspecific competition between the smaller plants in these populations (see also Villellas et al. 2013 for another short-lived species). The opposite trends in vital rates indicate the existence of demographic compensation between reproduction and recruitment in populations of $A$. vulneraria. Such compensatory changes in vital rates across the range are thought to allow species to occupy larger areas of distribution (Doak and Morris 2010; Villellas et al. 2015). Our results thus contribute to the increasing evidence that in contrast to the predictions of the ACM demographic compensation may be common in widespread species (Villellas et al. 2013, 2015; Peterson et al. 2018). 


\section{Plant size and density}

The size of plants as measured by their height and their number of flowerheads decreased with both altitude and latitude. A similar pattern has been found in many other species (e.g. Woodward 1986; Weber and Schmid 1998; Hargreaves et al. 2015). In contrast, in some forest herbs plant height increased with latitude (De Frenne et al. 2011; Acharya et al. 2017). For A. vulneraria, the results of the multiple regressions indicated that the reduced size of plants with increasing altitude and latitude is mainly due to the decrease in temperature. Temperature is an important constraint to growth and plant size is known to decrease with temperature and the resulting shorter growing season in many species (Körner 2003; De Frenne et al. 2013).

In contrast to plant size, plant density increased with both altitude and latitude. This could be an effect of reduced intraspecific competition due to the smaller size of plants. Furthermore, the density of $A$. vulneraria increased with lower soil nutrient levels along both gradients. Anthyllis vulneraria is a poor competitor (Sterk 1975) and negatively affected by high nutrient levels due to increased competition by other species (Ellenberg et al. 1992).

\section{Seed set and seed mass}

The lower seed set and reduced seed mass in high latitude populations of $A$. vulneraria could be due to several factors. First, plant size in A. vulneraria decreased with latitude and smaller plants often have lower seed set and smaller seeds due to resource limitation (Matthies 1990). In A. vulneraria the decrease in seed set with latitude was related to lower soil nutrients and temperatures, in line with the result of other studies (Moles and Westoby 2003; Wu et al. 2018). Second, the diversity and abundance of insect pollinators are reduced at high latitudes and dominated by Diptera (Elberling and Olesen 1999; Fulkerson et al. 2012). Because the flowers of $A$. vulneraria are exclusively pollinated by Hymenoptera (Couderc and Gorenflot 1978), seed set in the northern populations may have been lower due to a lack of pollen. Third, pollen limitation may result in increased selffertilization and increased abortion of developing seeds and lower seed mass at higher latitudes.

While seed set and seed mass decreased with latitude, they did not vary consistently with altitude and temperature. As in other plant species (Körner et al. 1989; Guo et al. 2010) the size of plants of $A$. vulneraria declined with altitude, but this did not result in a decline of seed set and mass. Instead, both reproductive components were highly variable at all altitudes, confirming that local environmental variation may strongly influence reproduction in A. vulneraria (Kesselring et al. 2015). Environmental factors may also interact with pollen availability to determine reproduction in alpine environments (Totland 2001). The few other studies that have investigated the relationship between seed set and altitude have found conflicting results (Totland and Birks 1996; Vaupel and Matthies 2012; Hargreaves et al. 2015). Similarly, studies that have investigated how mean seed mass varies with altitude in individual species found also no consistent pattern. In some species, seed mass increased (Holm 1994; Olejniczak et al. 2018), whereas in others it declined (Totland and Birks 1996; Pluess et al. 2005; Guo et al. 2010; Olejniczak et al. 2018), or showed no relationship with altitude (Holm 1994; Pluess et al. 2005; Vaupel and Matthies 2012; Olejniczak et al. 2018).

\section{Seed predation}

The seeds of $A$. vulneraria are attacked by several species of specific insect herbivores, e.g. Cupido minimus, Hypera trilineata, Tychius sp., Bruchophagus sp. (Sterk et al. 1982). Pre-dispersal seed predation decreased both along the latitudinal and the altitudinal gradient, although population size increased with altitude and plant density increased along both gradients. Larger and denser plant populations are more likely to be found by specific seed predators and to sustain viable populations of them (Kéry et al. 2001; Colling and Matthies 2004; Vaupel and Matthies 2012). In contrast to our results, the level of seed predation would thus have been expected to increase along the two gradients. The lower seed predation at high elevations and latitudes is most likely due to low temperatures and short summers that negatively affect larval development and abundance (Alonso 1999; Hodkinson 2005; Lee and Kotanen 2015). Our results are in line with those of many other studies that found a decrease in seed predation with increasing altitude (Alonso 1999; Giménez-Benavides et al. 2008; Buckley et al. 2019) and the few that studied effects of latitude (Vergeer and Kunin 2011; Lee and Kotanen 2015; but see Anstett et al. 2014). Our results indicate that the positive effects of increased density and larger population size of the host species A. vulneraria cannot compensate for the negative effects of the more severe weather conditions on the populations of the seed predators and support the notion of a general decline of the importance of insect herbivory with increasing latitude (Schemske et al. 2009).

\section{Population structure}

Anthyllis vulneraria is usually considered a biennial, which in the first year produces a rosette that in the second year flowers, fruits and then dies (Sterk 1975). In the current study, the proportion of flowering plants decreased strongly along the latitudinal gradient. A possible explanation for the high proportion of vegetative plants in the North could be the higher recruitment due to higher soil moisture, leading 
to an increase in the density of young vegetative plants in combination with a high mortality of vegetative plants over winter (Villellas et al. 2013). Alternatively, plants in the North may stay in a vegetative state for more than one year because flowering is delayed because of lower solar radiation, temperatures and nutrient availability (Lacey 1988; Lempe et al. 2005, but see Vergeer and Kunin 2011). This would increase the proportion of non-flowering plants over multiple growing and germination seasons as they accumulate in the population (Lacey 1988; Becker et al. 2006). In contrast, although similar environmental changes could be expected along the altitudinal gradient, at high altitudes both populations with a low and a high proportion of flowering plants were found. This indicates heterogeneity in local conditions (e.g. snow cover and time of snow melt) at a smaller scale than the Worldclim data that override the effects of general trends in climatic and edaphic conditions. Heterogeneity of small-scale habitat conditions is particularly high in alpine habitats (Körner 2007).

\section{Conclusions}

Our study of variation in population mean traits along two gradients from the centre of the distribution of $A$. vulneraria in Central Europe to its range margins in the subarctic North and at the high altitudes in the Alps only partially support the abundant centre model (ACM). The reduced size and reproduction of $A$. vulneraria in peripheral populations were in line with the decline in performance towards the range margins predicted by the ACM. However, the increase of recruitment and plant density towards the range limits contributes to the growing evidence that the general decline in vital rates towards the periphery assumed by the ACM is too simplistic (Abeli et al. 2014; Pironon et al. 2017). Instead, demographic compensation between vital rates, as between reduced reproduction and increased recruitment in A. vulneraria, may be an important factor contributing to the large area of distribution and wide altitudinal range of a species (Doak and Morris 2010). The plasticity of the life cycle might also provide some buffering for widespread species against negative effects of climate change (Doak and Morris 2010; Villellas et al. 2015; Peterson et al. 2018, but see Sheth and Angert 2018).

Population characteristics of A. vulneraria varied strongly along the altitudinal and latitudinal gradients and environmental conditions influenced mean population traits, population structure and demography. Changes in temperature along the gradients appeared to have by far the strongest effects on the populations, followed by those in other climate variables like precipitation and solar radiation, and in soil nutrients. Increasing altitude and latitude both reduced size-related traits of plants and seed predation, but only with latitude was there a clinal decline in the proportion of plants flowering, and in seed set and seed mass. Observed latitudinal patterns in population characteristics are thus of only limited value to predict changes with altitude. This indicates that it will be more difficult to draw conclusions about potential impacts of future climate warming on plant populations in mountains, because of large local variation in important traits not related to altitude and annual mean temperature, but to small-scale variation in environmental conditions (Scherrer and Körner 2010; Oldfather and Ackerly 2019) and potentially in plant-pollinator interactions (Totland and Birks 1996). However, the actual responses of species to predicted climate warming will also depend on the genetic variation among populations and their phenotypic plasticity (Peterson et al. 2018). Our study did not allow us to disentangle the effects of phenotypic plasticity, genetic variation and local adaptation. Common garden experiments and molecular genetic analyses will be necessary to identify the mechanisms involved.

Supplementary Information The online version contains supplementary material available at https://doi.org/10.1007/s00442-021-05030-6.

Acknowledgements The authors thank Béatrice Feider and Stéphanie Weis for assistance during fieldwork. We also thank the Ministère du Développement durable et des Infrastructures, Luxembourg for permission to collect samples of the legally protected Anthyllis vulneraria in Luxembourg and the Administration des services techniques de l'agriculture for analysing the soil samples. Two anonymous referees made valuable comments on earlier versions of the manuscript.

Author contribution statement LD, GC and DM conceived the study, analysed the data and prepared the manuscript; LD conducted field work and collected the data. All authors contributed critically to the drafts and gave final approval for publication.

Funding Open Access funding enabled and organized by Projekt DEAL. This study was funded by the National Research Fund of Luxembourg (Grant no. 7871584) and by Musée national d'histoire naturelle Luxembourg.

\section{Declarations}

Conflict of interest The authors declare that they have no conflict of interest.

Open Access This article is licensed under a Creative Commons Attribution 4.0 International License, which permits use, sharing, adaptation, distribution and reproduction in any medium or format, as long as you give appropriate credit to the original author(s) and the source, provide a link to the Creative Commons licence, and indicate if changes were made. The images or other third party material in this article are included in the article's Creative Commons licence, unless indicated otherwise in a credit line to the material. If material is not included in the article's Creative Commons licence and your intended use is not permitted by statutory regulation or exceeds the permitted use, you will need to obtain permission directly from the copyright holder. To view a copy of this licence, visit http://creativecommons.org/licenses/by/4.0/. 


\section{References}

Abeli T, Gentili R, Mondoni A, Orsenigo S, Rossi G (2014) Effects of marginality on plant population performance. J Biogeogr 41:239249. https://doi.org/10.1111/jbi.12215

Acharya KP, De Frenne P, Brunet J, Chabrerie O, Cousins SAO, Diekmann M, Hermy M, Kolb A, Lemke I, Plue J, Verheyen K, Graae BJ (2017) Latitudinal variation of life-history traits of an exotic and a native impatiens species in Europe. Acta Oecol 81:40-47. https://doi.org/10.1016/j.actao.2017.05.002

Alonso C (1999) Variation in herbivory by Yponomeuta mahalebella on its only host plant Prunus mahaleb along an elevational gradient. Ecol Entomol 24:371-379. https://doi.org/10.1046/j.1365-2311. 1999.00211.x

Angert AL (2006) Demography of central and marginal populations of monkeyflowers (Mimulus cardinalis and M. lewisii). Ecology 87:2014-2025. https://doi.org/10.1890/0012-9658(2006)87[2014: DOCAMP]2.0.CO;2

Anstett DN, Naujokaitis-Lewis I, Johnson MTJ (2014) Latitudinal gradients in herbivory on Oenothera biennis vary according to herbivore guild and specialization. Ecology 95:2915-2923. https:// doi.org/10.1890/13-0932.1

Barton K (2019) MuMIn: multi-model inference. R package ver. 1.43.6. https://CRAN.R-project.org/package=MuMIn

Becker U, Colling G, Dostal P, Jakobsson A, Matthies D (2006) Local adaptation in the monocarpic perennial Carlina vulgaris at different spatial scales across Europe. Oecologia 150:506-518. https:// doi.org/10.1007/s00442-006-0534-9

Brown JH (1984) On the relationship between abundance and distribution of species. Am Nat 124:255-279. https://doi.org/10. $1086 / 284267$

Buckley J, Widmer A, Mescher MC, Moraes CMD (2019) Variation in growth and defence traits among plant populations at different elevations: implications for adaptation to climate change. $\mathrm{J}$ Ecol 107:2478-2492. https://doi.org/10.1111/1365-2745.13171

Burnham KP, Anderson DR (2002) Model selection and multimodal inference: a practical information-theoretic approach. Springer, New York

Colling G, Matthies D (2004) The effects of plant population size on the interactions between the endangered plant Scorzonera humilis, a specialised herbivore, and a phytopathogenic fungus. Oikos 105:71-78. https://doi.org/10.1111/j.0030-1299. 2004.12783.x

Conert HJ (1975) Leguminosae-Tropaelaceae. In: Hegi, Illustrierte Flora von Mittel-Europa, Band IV, Teil 3, Dicotyledones 2. Paul Parey, Berlin, pp 1114-1750

Couderc H (1971) Etude expérimentale de la reproduction de l'Anthyllis vulneraria L. Bull Soc Bot France 118:359-373. https://doi.org/10.1080/00378941.1971.10838912

Couderc H, Gorenflot R (1978) Adaptation de la fleur entomophile de l'Anthyllis vulneraria L. à l'autogamie. Bull Soc Bot France 125:369-378. https://doi.org/10.1080/00378941.1978.10839462

Crawley MJ (2009) The R book, reprinted with corrections. Wiley, Chichester

Cullen J (1968) Anthyllis L. In: Tutin TG et al (eds) Flora Europaea Vol. 2. Rosaceae to umbelliferae. Cambridge University Press, Cambridge, pp 179-181

De Frenne P, Graae BJ, Kolb A, Shevtsova A, Baeten L, Brunet J, Chabrerie O, Cousins SAO, Decocq G, Dhondt R, Diekmann M, Gruwez R, Heinken T, Hermy M, Öster M, Saguez R, Stanton S, Tack W, Vanhellemont M, Verheyen K (2011) An intraspecific application of the leaf-height-seed ecology strategy scheme to forest herbs along a latitudinal gradient. Ecography 34:132-140. https://doi.org/10.1111/j.1600-0587.2010.06399.x
De Frenne P, Graae BJ, Rodríguez-Sánchez F, Kolb A, Chabrerie O, Decocq G, Kort H, Schrijver A, Diekmann M, Eriksson O, Gruwez R, Hermy M, Lenoir J, Plue J, Coomes DA, Verheyen K (2013) Latitudinal gradients as natural laboratories to infer species' responses to temperature. J Ecol 101:784-795. https://doi. org/10.1111/1365-2745.12074

Diedenhofen B, Musch J (2015) cocor: A comprehensive solution for the statistical comparison of correlations. PLoS ONE 10:e0121945. https://doi.org/10.1371/journal.pone.0121945

Doak DF, Morris WF (2010) Demographic compensation and tipping points in climate-induced range shifts. Nature 467:959-962. https://doi.org/10.1038/nature09439

Elberling H, Olesen JM (1999) The structure of a high latitude plantflower visitor system: the dominance of flies. Ecography 22:314 323. https://doi.org/10.1111/j.1600-0587.1999.tb00507.x

Ellenberg H, Weber HE, Düll R, Wirth V, Werner W, Paulißen D (1992) Zeigerwerte von pflanzen in mitteleuropa. Scr Geobot 18:1-248

Erschbamer B, Retter V (2004) How long can glacier foreland species live? Flora 199:500-504. https://doi.org/10.1078/ 0367-2530-00178

Fick SE, Hijmans RJ (2017) WorldClim 2: new 1-km spatial resolution climate surfaces for global land areas. Int J Climatol 37:43024315. https://doi.org/10.1002/joc.5086

Fulkerson JR, Whittall JB, Carlson ML (2012) Reproductive ecology and severe pollen limitation in the polychromic tundra plant, Parrya nudicaulis (Brassicaceae). PLoS ONE 7:e32790. https://doi. org/10.1371/journal.pone.0032790

GBIF.org (2019) GBIF Occurrence Download. https://doi.org/10. $15468 / \mathrm{dl} .1 \mathrm{n} 1 \mathrm{pfa}$

Giménez-Benavides L, Escudero A, Iriondo JM (2008) What shapes the altitudinal range of a high mountain Mediterranean plant? Recruitment probabilities from ovule to seedling stage. Ecography 31:731-740. https://doi.org/10.1111/j.0906-7590.2008.05509.x

Grace JB, Johnson DJ, Lefcheck JS, Byrnes JEK (2018) Quantifying relative importance: computing standardized effects in models with binary outcomes. Ecosphere 9:e02283. https://doi.org/10. $1002 /$ ecs 2.2283

Guo H, Mazer SJ, Du G (2010) Geographic variation in seed mass within and among nine species of Pedicularis (Orobanchaceae): effects of elevation, plant size and seed number per fruit. J Ecol 98:1232-1242. https://doi.org/10.1111/j.1365-2745.2010.01688.x

Halbritter AH, Alexander JM, Edwards PJ, Billeter R (2013) How comparable are species distributions along elevational and latitudinal climate gradients? Global Ecol Biogeogr 22:1228-1237. https:// doi.org/10.1111/geb.12066

Hargreaves AL, Weiner JL, Eckert CG (2015) High-elevation range limit of an annual herb is neither caused nor reinforced by declining pollinator service. J Ecol 103:572-584. https://doi.org/10. $1111 / 1365-2745.12377$

Hodkinson ID (2005) Terrestrial insects along elevation gradients: species and community responses to altitude. Biol Rev 80:489-513. https://doi.org/10.1017/S1464793105006767

Holm S-O (1994) Reproductive patterns of Betula pendula and B. pubescens coll. along a regional altitudinal gradient in northern Sweden. Ecography 17:60-72. https://doi.org/10.1111/j.16000587.1994.tb00077.x

Honnay O, Coart E, Butaye J, Adriaens D, Van Glabeke S, RoldánRuiz I (2006) Low impact of present and historical landscape configuration on the genetics of fragmented Anthyllis vulneraria populations. Biol Cons 127:411-419. https://doi.org/10.1016/j. biocon.2005.09.006

IPCC (2014) Climate change 2014: synthesis report. Contribution of working groups I, II and III to the fifth assessment report of the intergovernmental panel on climate change. In: Core Writing Team, Pachauri RK, Meyer LA (eds). Geneva, Switzerland 
Jansen F, Bonn A, Bowler DE, Bruelheide H, Eichenberg D (2019) Moderately common plants show highest relative losses. Conserv Lett 2019:12674. https://doi.org/10.1111/conl.12674

Jump AS, Woodward FI (2003) Seed production and population density decline approaching the range-edge of Cirsium species. New Phytol 160:349-358. https://doi.org/10.1046/j.1469-8137.2003. 00873.x

Jump AS, Mátyás C, Peñuelas J (2009) The altitude-for-latitude disparity in the range retractions of woody species. Trends Ecol Evol 24:694-701. https://doi.org/10.1016/j.tree.2009.06.007

Kéry M, Matthies D, Fischer M (2001) The effect of plant population size on the interactions between the rare plant Gentiana cruciata and its specialized herbivore Maculinea rebeli: Interaction between a rare gentian and a butterfly. J Ecol 89:418-427. https:// doi.org/10.1046/j.1365-2745.2001.00550.x

Kesselring H, Armbruster GFJ, Hamann E, Stöcklin J (2015) Past selection explains differentiation in flowering phenology of nearby populations of a common alpine plant. Alp Bot 125:113-124. https://doi.org/10.1007/s00035-015-0157-z

Körner C (2003) Alpine plant life: functional plant ecology of high mountain ecosystems, 2nd edn. Springer, Berlin

Körner C (2007) The use of 'altitude' in ecological research. Trends Ecol Evol 22:569-574. https://doi.org/10.1016/j.tree.2007.09.006

Körner C, Neumayer M, Menendez-Riedl SP, Smeets-Scheel A (1989) Functional morphology of mountain plants. Flora 182:353-383. https://doi.org/10.1016/S0367-2530(17)30426-7

Köster E, Bitocchi E, Papa R, Pihu S (2008) Genetic structure of the Anthyllis vulneraria L. s. 1. species complex in Estonia based on AFLPs. Cent Eur J Biol 3:442-450. https://doi.org/10.2478/ s11535-008-0033-6

Krauss J, Steffan-Dewenter I, Tscharntke T (2004) Landscape occupancy and local population size depends on host plant distribution in the butterfly Cupido minimus. Biol Conserv 120:355361. https://doi.org/10.1016/j.biocon.2004.03.007

Lacey EP (1988) Latitudinal variation in reproductive timing of a short-lived monocarp, Daucus carota (Apiaceae). Ecology 69:220-232. https://doi.org/10.2307/1943178

Lee Y, Kotanen PM (2015) Differences in herbivore damage and performance among Arctium minus (burdock) genotypes sampled from a geographic gradient: a common garden experiment. Biol Invasions 17:397-408. https://doi.org/10.1007/ s10530-014-0737-7

Lempe J, Balasubramanian S, Sureshkumar S, Singh A, Schmid M, Weigel D (2005) Diversity of flowering responses in wild Arabidopsis thaliana strains. PLoS Genet 1:e6. https://doi.org/10.1371/ journal.pgen.0010006

Matthies D (1990) Plasticity of reproductive components at different stages of development in the annual plant Thlaspi arvense L. Oecologia 83:105-116. https://doi.org/10.1007/BF00324641

Moeller DA, Runquist RDB, Moe AM, Geber MA, Goodwillie C, Cheptou PO, Eckert CG, Elle E, Johnston MO, Kalisz S, Ree RH, Sargent RD, Vallejo-Marin M, Winn AA (2017) Global biogeography of mating system variation in seed plants. Ecol Lett 20:375-384. https://doi.org/10.1111/ele.12738

Moles AT, Westoby M (2003) Latitude, seed predation and seed mass. J Biogeogr 30:105-128. https://doi.org/10.1046/j.1365-2699.2003. 00781.X

Nanni L, Ferradini N, Taffetani F, Papa R (2004) Molecular phylogeny of Anthyllis spp. Plant Biol 6:454-464. https://doi.org/10. 1055/s-2004-820968

Oldfather MF, Ackerly DD (2019) Microclimate and demography interact to shape stable population dynamics across the range of an alpine plant. New Phytol 222:193-205. https://doi.org/10.1111/ nph. 15565

Olejniczak P, Czarnoleski M, Delimat A, Majcher BM, Szczepka K (2018) Seed size in mountain herbaceous plants changes with elevation in a species-specific manner. PLoS ONE 13:e0199224. https://doi.org/10.1371/journal.pone.0199224

Pellissier L, Fournier B, Guisan A, Vittoz P (2010) Plant traits co-vary with altitude in grasslands and forests in the European Alps. Plant Ecol 211:351-365. https://doi.org/10.1007/s11258-010-9794-x

Peterson ML, Doak DF, Morris WF (2018) Both life-history plasticity and local adaptation will shape range-wide responses to climate warming in the tundra plant Silene acaulis. Glob Change Biol 24:1614-1625. https://doi.org/10.1111/gcb.13990

Pironon S, Papuga G, Villellas J, Angert AL, García MB, Thompson JD (2017) Geographic variation in genetic and demographic performance: new insights from an old biogeographical paradigm: The centre-periphery hypothesis. Biol Rev 92:1877-1909. https://doi. org/10.1111/brv.12313

Pluess AR, Schütz W, Stöcklin J (2005) Seed weight increases with altitude in the Swiss Alps between related species but not among populations of individual species. Oecologia 144:55-61. https:// doi.org/10.1007/s00442-005-0047-y

R Core Team (2018) R: a language and environment for statistical computing. In: R Foundation for Statistical Computing, Vienna, Austria. https://www.R-project.org/

Rasmann S, Pellissier L, Defossez E, Jactel H, Kunstler G (2014) Climate-driven change in plant-insect interactions along elevation gradients. Funct Ecol 28:46-54. https://doi.org/10.1111/ 1365-2435.12135

Sagarin RD, Gaines SD (2002) The 'abundant centre' distribution: to what extent is it a biogeographical rule? Ecol Lett 5:137-147. https://doi.org/10.1046/j.1461-0248.2002.00297.x

Sagarin RD, Gaines SD, Gaylord B (2006) Moving beyond assumptions to understand abundance distributions across the ranges of species. Trends Ecol Evol 21:524-530. https://doi.org/10. 1016/j.tree.2006.06.008

Schemske DW, Mittelbach GG, Cornell HV, Sobel JM, Roy K (2009) Is there a latitudinal gradient in the importance of biotic interactions? Annu Rev Ecol Evol Syst 40:245-269. https://doi.org/10. 1146/annurev.ecolsys.39.110707.173430

Scherrer D, Körner C (2010) Infra-red thermometry of alpine landscapes challenges climatic warming projections. Glob Change Biol 16:2602-2613. https://doi.org/10.1111/j.1365-2486.2009. 02122.x

Sheth SN, Angert AL (2018) Demographic compensation does not rescue populations at a trailing range edge. PNAS 115:24132418. https://doi.org/10.1073/pnas.1715899115

Siefert A, Lesser MR, Fridley JD (2015) How do climate and dispersal traits limit ranges of tree species along latitudinal and elevational gradients? Glob Ecol Biogeogr 24:581-593. https:// doi.org/10.1111/geb.12287

Sterk AA (1975) Demographic studies of Anthyllis vulneraria L. in the Netherlands. Acta Bot Neerl 24:315-337

Sterk AA, Van Duijkeren A, Hogervorst J, Verbeek EDM (1982) Demographic studies of Anthyllis vulneraria L. in the Netherlands: II. Population density fluctuations and adaptations to arid conditions, seed populations, seedling mortality, and influence of the biocenosis on demographic features. Acta Bot Neerl 31:11-40. https://doi.org/10.1111/j.1438-8677.1982.tb01590.x

Swab RM, Regan HM, Matthies D, Becker U, Bruun HH (2015) The role of demography, intra-species variation, and species distribution models in species' projections under climate change. Ecography 38:221-230. https://doi.org/10.1111/ecog.00585

Thomas CD (2010) Climate, climate change and range boundaries. Divers Distrib 16:488-495. https://doi.org/10.1111/j.14724642.2010.00642.x

Totland $\varnothing$ (2001) Environment-dependent pollen limitation and selection on floral traits in an alpine species. Ecology 82:22332244. https://doi.org/10.1890/0012-9658(2001)082[2233:EDPLAS]2.0.CO;2 
Totland Ø, Birks HJB (1996) Factors influencing inter-population variation in Ranunculus acris seed production in an alpine area of southwestern Norway. Ecography 19:269-278. https://doi. org/10.1111/j.1600-0587.1996.tb01254.x

Van Glabeke S, Coart E, Honnay O, Roldán-Ruiz I (2007) PRIMER NOTE: Isolation and characterization of polymorphic microsatellite markers in Anthyllis vulneraria. Mol Ecol Notes 7:477479. https://doi.org/10.1111/j.1471-8286.2006.01625.x

Vaupel A, Matthies D (2012) Abundance, reproduction, and seed predation of an alpine plant decrease from the center toward the range limit. Ecology 93:2253-2262. https://doi.org/10.1890/ 11-2026.1

Vergeer P, Kunin WE (2011) Life history variation in Arabidopsis lyrata across its range: effects of climate, population size and herbivory. Oikos 120:979-990. https://doi.org/10.1111/j.16000706.2010.18944.x

Villellas J, Ehrlén J, Olesen JM, Braza R, García MB (2013) Plant performance in central and northern peripheral populations of the widespread Plantago coronopus. Ecography 36:136-145. https://doi.org/10.1111/j.1600-0587.2012.07425.x
Villellas J, Doak DF, García MB, Morris WF (2015) Demographic compensation among populations: what is it, how does it arise and what are its implications? Ecol Lett 18:1139-1152. https:// doi.org/10.1111/ele.12505

Walther G-R (2003) Plants in a warmer world. Perspect Plant Ecol Evol Syst 6:169-185. https://doi.org/10.1078/1433-8319-00076

Weber E, Schmid B (1998) Latitudinal population differentiation in two species of Solidago (Asteraceae) introduced into Europe. Am J Bot 85:1110-1121. https://doi.org/10.2307/2446344

Woodward FI (1986) Ecophysiological studies on the shrub Vaccinium myrtillus $\mathrm{L}$. taken from a wide altitudinal range. Oecologia 70:580-586. https://doi.org/10.1007/BF00379908

Woodward FI (1987) Climate and plant distribution. Cambridge University Press, Cambridge

Wu H, Meng H, Wang S et al (2018) Geographic patterns and environmental drivers of seed traits of a relict tree species. For Ecol Manage 422:59-68. https://doi.org/10.1016/j.foreco.2018.04.003 